\title{
Effectiveness and safety of the enhanced recovery program in colorectal surgery: overview of systematic reviews
}

\section{Efectividad y seguridad del programa multimodal perioperatorio en cirugía colorrectal: Revisión sistemática de revisiones}

\section{Kelly Rocío Chacón Acevedo (D) ,Édgar Cortés Reyes (D), Óscar Alexander Guevara Cruz,} Jorge Augusto Díaz Rojas, Lina María Rincón Martínez

Clinical Epidemiology Master's Program, Clinical Research Institute, Medical School, Universidad Nacional de Colombia. Bogotá, Colombia.

Correspondence: Universidad Nacional de Colombia. Facultad de Medicina. Instituto de Investigaciones Clínicas, Ciudad Universitaria. Bogotá, Colombia. Email:krchacona@unal.edu.co

\section{Abstract}

\section{What do we know about this} problem?

The number of surgical procedures is increasing worldwide. Colorectal surgery as treatment for colorectal diseases is associated with postoperative complications and prolonged hospital length of stay.

What is the contribution of this study?

This study provides clinical experts with better and more up-to-date evidence regarding multimodal enhanced recovery programs focused on critical outcomes in colorectal surgery.

\section{How to cite this article:}

Chacón Acevedo KR, Cortés Reyes É, Guevara Cruz ÓA, Díaz Rojas JA, Rincón Martínez LM. Effectiveness and safety of the enhanced recovery program in colorectal surgery: overview of systematic reviews. Colombian Journal of Anesthesiology. 2021;49(1):e943

\section{Introduction}

Multimodal enhanced recovery programs are a new paradigm in perioperative care.

\section{Objective}

To evaluate the certainty of evidence pertaining to the effectiveness and safety of the multimodal perioperative care program in elective colorectal surgery.

Data source: A search was conducted in the Medline, EMBASE, and Cochrane databases, up until February 2020.

\section{Eligibility criteria}

Systematic reviews that take into account the perioperative multimodal program in patients with an indication for colorectal surgery were included. The primary outcomes were morbidity and postoperative deaths. The secondary outcome was hospital length of stay.

\section{Study quality and synthesis method}

The reviews were evaluated with AMSTAR-2 and the certainty of the evidence with the GRADE methodology. The findings are presented with measures of frequency, risk estimators, or differences.

\section{Results}

Six systematic reviews of clinical trials with medium and high quality in AMSTAR-2 were included. Morbidity was reduced between 16 and $48 \%$. Studies are inconclusive regarding postoperative mortality. Hospital length of stay was reduced by an average of 2.5 days $(p<0.05)$. The certainty of the body of evidence is very low.

\section{Limitations}

The effect of the program, depending on the combination of elements, is not clear.

\section{Conclusions and implications}

Despite the proven evidence that the program is effective in reducing global postoperative morbidity and hospital stay, the body of evidence is of very low quality. Consequently, results may change with new evidence and further research is required.

\section{Keywords}

Colorectal surgery; perioperative care; enhanced recovery; systematic reviews; health technology assessment. 


\section{Resumen}

Introducción

Los programas multimodales de cuidado perioperatorio son nuevos paradigmas de atención en salud, particularmente en el paciente quirúrgico.

\section{Objetivo}

Evaluar la certeza en la evidencia de la efectividad y seguridad del programa multimodal perioperatorio en cirugía colorrectal electiva.

\section{Fuente de datos}

Se consultaron las bases de datos Medline, EMBASE y Cochrane hasta febrero de 2020.

\section{Criterios de elegibilidad}

Se incluyeron revisiones sistemáticas que consideraron como intervención el programa multimodal perioperatorio en pacientes con indicación de cirugía colorrectal. Los desenlaces primarios fueron morbilidad y mortalidad postoperatoria. El desenlace secundario fue estancia hospitalaria.

\section{Evaluación de los estudios y método de síntesis}

La calidad de las revisiones fue evaluada con AMSTAR-2 y la certeza de la evidencia con la metodología GRADE. Los hallazgos se presentan con medidas de frecuencia, estimadores de riesgo o diferencias.

\section{Resultados}

Se incluyeron seis revisiones sistemáticas de ensayos clínicos de media y alta calidad en AMSTAR-2. La morbilidad se redujo entre el 16 y el $48 \%$. Para la mortalidad postoperatoria no se reportan diferencias a favor del programa. La estancia hospitalaria se redujo en promedio 2,5 días ( $p<0,05$ ). La certeza del cuerpo de la evidencia es muy baja.

\section{Limitaciones}

El efecto del programa en función de combinación de elementos no es claro.

\section{Conclusiones e implicaciones}

A pesar de que la evidencia sugiere que el programa es efectivo en la reducción de morbilidad postoperatoria global y estancia hospitalaria, el cuerpo de la evidencia es de muy baja calidad, por lo que los resultados podrían cambiar con nueva evidencia. Se requieren nuevas investigaciones.

\section{Palabras clave}

Cirugía colorrectal; revisión sistemática; programas de rápida recuperación; cuidado perioperatorio, evaluación de tecnología sanitaria.

\section{INTRODUCTION}

Over the past decade, there has been an increase of approximately $33 \%$ in the number of surgical procedures worldwide (1). At the same time, important advances have been made in colorectal surgery, although challenges still remain, mainly as refers to the high frequency of postoperative complications in up to $40 \%$ of patients, requiring prolonged hospital length of stay (LOS) (2) and resulting in up to a four-fold increase in care costs (3).

The multimodal perioperative care program, also known as enhanced recovery after surgery (ERAS), emerges as a health technology designed to reduce surgical stress and postoperative morbidity by means of standardization of preoperative, intraoperative and postoperative care components based on the best available evidence (4). Colorectal surgery is the setting in which greatest development and widespread use of the program has been achieved, mainly in high income countries (5-8), as evidenced by the large number of publications on the topic (4). However, there is still broad variability in clinical practice, and outcomes following colorectal surgery continue to be challenging, probably due to methodological limitations in the body of evidence which have not been examined to this date

In this regard, there is a need to determine the true impact of the program on health outcomes, as well as the certainty of these results for decision-making on its potential implementation and allocation of resources for perioperative care. The objective of this research was to assess the certainty of evidence and the size of the effectiveness and safety of the multimodal perioperative program in elective colorectal surgery.

\section{METHODS}

A systematic literature review (SLR) was conducted in accordance with the protocol established and approved by the Ethics Committee of the Universidad Nacional of Colombia Medical School. The report of this review complies with the completeness recommendations contained in the PRISMA statement.

The search for evidence was conducted in the Medline (Ovid), Embase and Cochrane databases using the terms colorectal, colon, colonic, rectum, sigmoid, rectal, colorectal, fast-track, enhanced recovery surgery (ERAS), surgical, procedure, resection, laparoscopic. The search strategies are shown in Complemenatry content A. Also, the review looked into the references of the included studies through manual search, theses, research papers and abstracts. Searches were not limited by language 
or date of publication and included publications up until February 2020.

The following were the inclusion criteria: a) Reports of systematic reviews and/or meta-analyses of moderate confidence (non-compliance of up to one critical criterion, different from the search strategy and study selection, and from reporting of risk of bias assessment of primary studies included) according to the AMSTAR-2 tool; b) reports of randomized clinical trials (RCTs) and controlled clinical trials (CCT) or observational studies in case of not finding systematic literature reviews (SLRs); c) inclusion of adult populations ( $>18$ years) taken to elective colorectal surgery under a multimodal perioperative care program, compared to standard care. The program was defined as standardized perioperative management in colorectal surgery, including enhanced recovery programs (ERAS) or fast-track programs. Studies were excluded if the multimodal program did not include elements of the three phases of the perioperative period, if they had methodological limitations that compromised the confidence of the results, and if they did not report risk of bias of the primary studies included.

Primary outcomes were morbidity or complications, and postoperative mortality. Secondary outcomes were length of hospital stay (LOS) and readmission rate.

Two reviewers working independently selected the articles based on titles and abstracts; for articles with selection potential, full-texts were obtained and read, verifying eligibility criteria; disagreements were solved by consensus between the two reviewers. The methodological quality of the SLRs was reviewed by the same two researchers using A MeaSurement Tool to Assess Systematic Reviews (AMSTAR), version 2 (9). Modifications to the categories of the tool were considered, as follows: moderate confidence, non-compliance with up to one critical criterion other than the search and study selection strategy and the risk of bias of primary studies included; low confidence, non-compliance with up to two critical criteria; and those that did not fall in these categories were considered to be of critically low confidence, while partial yes assessments were considered compliant. The high confidence category was maintained as defined by the tool. One of the reviewers used a specific form to enter the data of interest for moderate and high confidence SLRs, while another researcher verified the information.

The body of evidence was defined as the best quality and more updated SLR (maximum 5 years since publication until the search date) that answered the research question, in accordance with the proposal by Gaitan et al. (10). The GRADE method, through the application of CRADE pro, was used to assess the certainty of the results for the body of evidence (11).

\section{Statistical analysis and information synthesis}

A narrative synthesis of the findings in the included studies was made. Frequency and association measures were reported, including relative risk (RR), odds ratio (OR), hazard ratio (HR) and mean differences (MD), with $95 \%$ confidence intervals, when available in the papers included.

This article is the result of an original research carried out as a prerequisite to obtain a Master's degree in Clinical Epidemiology from the Universidad Nacional of Colombia. It was approved by the Ethics and Research Committee of the Universidad Nacional of Colombia of Medicine School. It is considered a risk-free research, as it is a synthesis of retrospective published information with no changes in the variables of actual individuals. No animal or human experiments were conducted.

\section{RESULTS}

Overall, 863 references were retrieved by the search. Of these, 33 were considered potentially eligible and the rest were excluded due to the reasons described in Figure 1. The full texts for the 33 were

FIGURE 1. PRISMA search, study selection and inclusion.

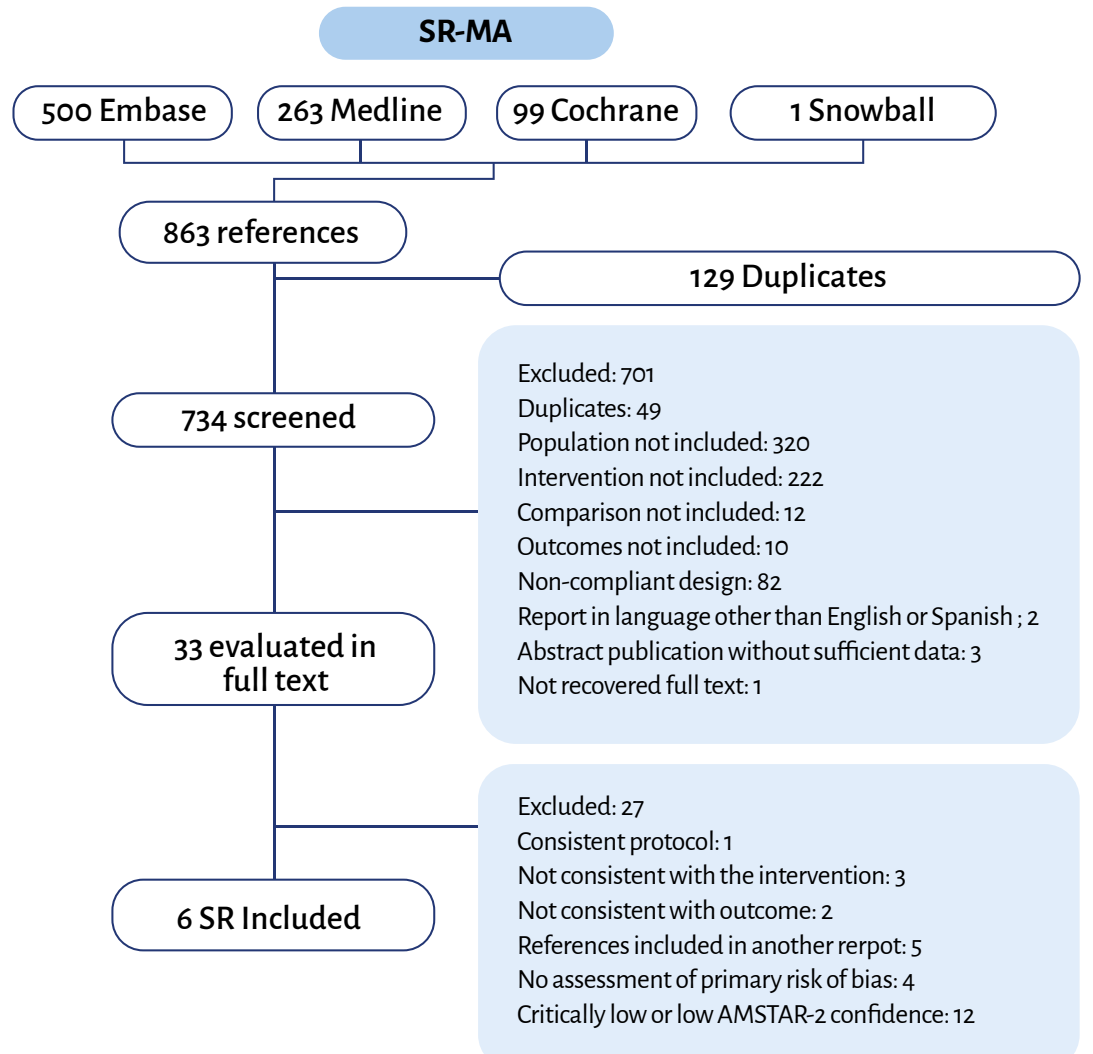

SR: Systematic reviews, SR-MA: Systematic reviews-Meta-analyses. SouRCE: Authors. 
TABLE 1. Characteristics of the included systematic literature reviews.

\begin{tabular}{|c|c|c|c|c|c|c|c|c|c|}
\hline Author & $\begin{array}{l}\text { Search } \\
\text { date }\end{array}$ & \multicolumn{2}{|c|}{ Queried databases } & Design & $\begin{array}{l}\text { Number } \\
\text { of studies } \\
\text { included }\end{array}$ & $\begin{array}{c}\text { ERAS/ } \\
\text { Traditional } \\
\text { care }\end{array}$ & $\begin{array}{l}\text { Meta- } \\
\text { analysis }\end{array}$ & $\begin{array}{c}\text { Risk of bias } \\
\text { tool }\end{array}$ & AMSTAR-2 \\
\hline \multirow{3}{*}{$\begin{array}{l}\text { Bagnall, } \\
2014 \underline{(16)}\end{array}$} & \multirow{3}{*}{$\begin{array}{l}\text { January } \\
1947- \\
\text { February } \\
2014\end{array}$} & \multicolumn{2}{|c|}{ Medline } & RTC & 2 & 234 & \multirow[t]{3}{*}{ No } & \multirow{3}{*}{$\begin{array}{l}\text { Quality } \\
\text { Index }\end{array}$} & \multirow[t]{3}{*}{$\mathrm{HICH}$} \\
\hline & & \multicolumn{2}{|c|}{ EMBASE } & Observational & 11 & 35 & & & \\
\hline & & \multicolumn{2}{|c|}{ CENTRAL } & & 3 & & & & \\
\hline $\begin{array}{c}\text { Greco, } 2013 \\
\underline{(12)}\end{array}$ & $\begin{array}{l}\text { Up to June } \\
2012\end{array}$ & \multicolumn{2}{|c|}{$\begin{array}{l}\text { BioMedCentral } \\
\text { PubMed } \\
\text { Scopus } \\
\text { CENTRAL }\end{array}$} & RTC & 16 & $1181 / 1195$ & Yes & $\begin{array}{l}\text { Cochrane } \\
\text { tool }\end{array}$ & MODERATE \\
\hline \multirow[t]{2}{*}{$\begin{array}{l}\text { Greer, } 2018 \\
\qquad \underline{(13)}\end{array}$} & \multirow[t]{2}{*}{$\begin{array}{c}2011 \text { - July } \\
2017\end{array}$} & \multicolumn{2}{|l|}{$\begin{array}{l}\text { Medline } \\
\text { (Ovid) } \\
\text { CINAHL }\end{array}$} & RTC & 22 & $2207 /$ & \multirow[t]{2}{*}{ Yes } & \multirow{2}{*}{$\begin{array}{l}\text { Modified } \\
\text { Cochrane } \\
\text { tool }\end{array}$} & \multirow[t]{2}{*}{ MODERATE } \\
\hline & & \multicolumn{2}{|l|}{ CINAHL } & RTC & 3 & 2043 & & & \\
\hline $\begin{array}{c}\mathrm{Ni}, 2019 \\
\underline{(17)}\end{array}$ & $\begin{array}{l}\text { Up to } \\
\text { October } \\
2019\end{array}$ & \multicolumn{2}{|c|}{$\begin{array}{l}\text { PubMed } \\
\text { EMBASE } \\
\text { Cochrane Library } \\
\text { Web of Science } \\
\text { ClinicalTrials.gov }\end{array}$} & RTC & 13 & $639 / 659$ & Yes & $\begin{array}{l}\text { Modified } \\
\text { Cochrane } \\
\text { tool }\end{array}$ & MODERATE \\
\hline $\begin{array}{l}\text { Spanjers- } \\
\text { berg, } 2011 \\
\underline{(14)}\end{array}$ & Up to 2009 & $\begin{array}{l}\text { CDSR } \\
\text { DARE } \\
\text { CENTRAL } \\
\text { NHS } \\
\text { Economic } \\
\text { Evaluation } \\
\text { Database }\end{array}$ & $\begin{array}{l}\text { EMBASE } \\
\text { ISI Web of } \\
\text { Knowledge } \\
\text { (Web of } \\
\text { Science) } \\
\text { ASCRS } \\
\text { MEDLINE }\end{array}$ & RTC & 6 & $119 / 118$ & Yes & $\begin{array}{l}\text { Cochrane } \\
\text { tool }\end{array}$ & $\mathrm{HICH}$ \\
\hline $\begin{array}{l}\text { Zhuang, } \\
2013(15)\end{array}$ & $\begin{array}{c}\text { January } \\
1966 \text { - July } \\
2012\end{array}$ & \multicolumn{2}{|c|}{$\begin{array}{l}\text { Pubmed } \\
\text { EMBASE } \\
\text { CENTRAL }\end{array}$} & RTC & 13 & $953 / 957$ & Yes & $\begin{array}{l}\text { Cochrane } \\
\text { tool }\end{array}$ & MODERATE \\
\hline
\end{tabular}

ERAS: Enhanced recovery after surgery, RCT: Randomized clinical trial. souRCE: Authors.

assessed and, in the end, 6 SLRs were included (12-17). Exclusions are detailed in Complementary content $\mathrm{B}$.

\section{Description of included studies}

The characteristics of the included studies are shown in Table 1. The six SLRs included six RCT-type primary studies, one included both RCTs and CCTs (13) and one included RCTs and observational studies (16). For the literature search, four databases were queried on average. The median number of studies in each SLR was 14.5. Of the six included studies, five metaanalysis synthesized the information. One reference analyzed patients with cancer and benign condition as well as the surgical approach (13), a second one focused on the laparoscopic approach and a third one focused on adults 65 years or older (16). Five SLRs used the Cochrane risk of bias assessment tool and the Downs and Black
IQ Index to assess the quality of the included studies (16). Regarding SRL methodological quality, two were rated as high confidence $\underline{(14,16)}$ and the others were classified as moderate confidence in accordance with the modified AMSTAR- 2 .

The definition of the multimodal perioperative program in colorectal surgery was found to vary in terms of the items contained, with a range between four and eighteen items. The items found in the 
TABLE 2. Elements of the ERAS (enhanced recovery after surgery) program.

\begin{tabular}{|c|c|c|c|c|c|c|}
\hline Program elements & Bagnall (16) & Greco (12) & Greer (13) & $\mathrm{Ni} \underline{(17)}$ & Spanjersberg (14) & Zhuang (15) \\
\hline $\begin{array}{l}\text { Counseling, education and information prior to } \\
\qquad \text { admission }\end{array}$ & $\mathrm{x}$ & $x$ & $\mathrm{x}$ & $x$ & $\mathrm{x}$ & $x$ \\
\hline Nausea and vomiting prevention & $x$ & $x$ & $x$ & $x$ & & $x$ \\
\hline Preanesthetic medication avoidance & $x$ & $x$ & $x$ & $x$ & $x$ & $x$ \\
\hline Antimicrobial prophylaxis and skin preparation & $x$ & & $x$ & $x$ & & $x$ \\
\hline Bowel preparation avoidance & $x$ & $x$ & $x$ & $x$ & $x$ & $x$ \\
\hline Preoperative fluid and electrolyte therapy & & $x$ & & $x$ & $x$ & $x$ \\
\hline Antithrombotic prophylaxis & $x$ & $\mathrm{x}$ & $x$ & $x$ & & $x$ \\
\hline Symbiotics & & & & & $x$ & \\
\hline Preoperative fasting and carbohydrate loading & $x$ & $x$ & $x$ & $x$ & $x$ & $x$ \\
\hline Standard anesthesia protocol & $x$ & $x$ & $x$ & $x$ & & $x$ \\
\hline Intraoperative fluid and electrolyte therapy & $x$ & & $x$ & $x$ & & \\
\hline Hypothermia prevention & $x$ & $x$ & $x$ & $x$ & $x$ & $x$ \\
\hline Minimally invasive surgical approach & $x$ & $x$ & $x$ & $x$ & $x$ & $x$ \\
\hline Thoracic epidural & $x$ & $x$ & & & $x$ & \\
\hline High $\mathrm{O} 2$ concentrations & & & & & $x$ & \\
\hline Nasogastric tube removal & $x$ & $x$ & & $x$ & $x$ & $x$ \\
\hline Non-opioid postoperative analgesia & $x$ & & $x$ & $x$ & $x$ & $x$ \\
\hline Postoperative fluid and electrolyte therapy & & & $x$ & $x$ & & \\
\hline Early urinary catheter removal & $x$ & $x$ & $x$ & $x$ & $x$ & $x$ \\
\hline Postoperative blood glucose monitoring & & & $x$ & $x$ & & \\
\hline Postoperative nutritional care & & & $x$ & & & $x$ \\
\hline Early mobilization & $x$ & & $x$ & $x$ & $x$ & $x$ \\
\hline Early food intake & $x$ & $x$ & $x$ & $x$ & $x$ & \\
\hline Prokinetics, ileus prevention & & & $x$ & $x$ & $x$ & $x$ \\
\hline No drains & $x$ & $x$ & $x$ & $x$ & $x$ & \\
\hline Audit & & & & & & $x$ \\
\hline
\end{tabular}

SOURCE: Authors.

six SLRs were: preadmission education, preanesthetic medication avoidance, mechanical bowel preparation and preoperative fasting, use of carbohydrate loading, hypothermia prevention, minimally invasive surgical approach, and early drain removal. The items gathered for each SLR are shown in Table 2. Morbidity or postoperative complications, LOS, readmission rates and mortality were outcomes of interest in all SLRs. Other outcomes included ileus, surgical site infection, time to first flatus, ambulation and oral intake initiation.
Table 3 shows the results of the outcomes assessed in each of the SLRs included.

\section{Complications and/or morbidity}

The study by Bagnall et al., which gathered information on elderly patients, found a range of complications between $5 \%$ and $27 \%$ in the ERAS groups, as compared to a range of 21 to $59 \%$ in the groups receiving standard care $(p<0.05)$ (16). A similar direction of the effect in favor of the ERAS group was found in the studies by Greco et al., Greer et al., Spanjersberg et al. and Zhuang et al., reporting a reduction in the risk of postoperative (POP) complications between $39 \%$ and $48 \%$ (12-15).

In terms of the complexity of the complications, Spanjersberg et al. did not find differences in major and minor complications between the groups ( $p=$ 0.34). In contrast, there was a difference in overall complications in favor of the ERAS program, with $58 \%$ risk reduction ( $p=0.003$ ) (14). Greco made a distinction 
TABLE 3. Primary results of the included systematic literature reviews.

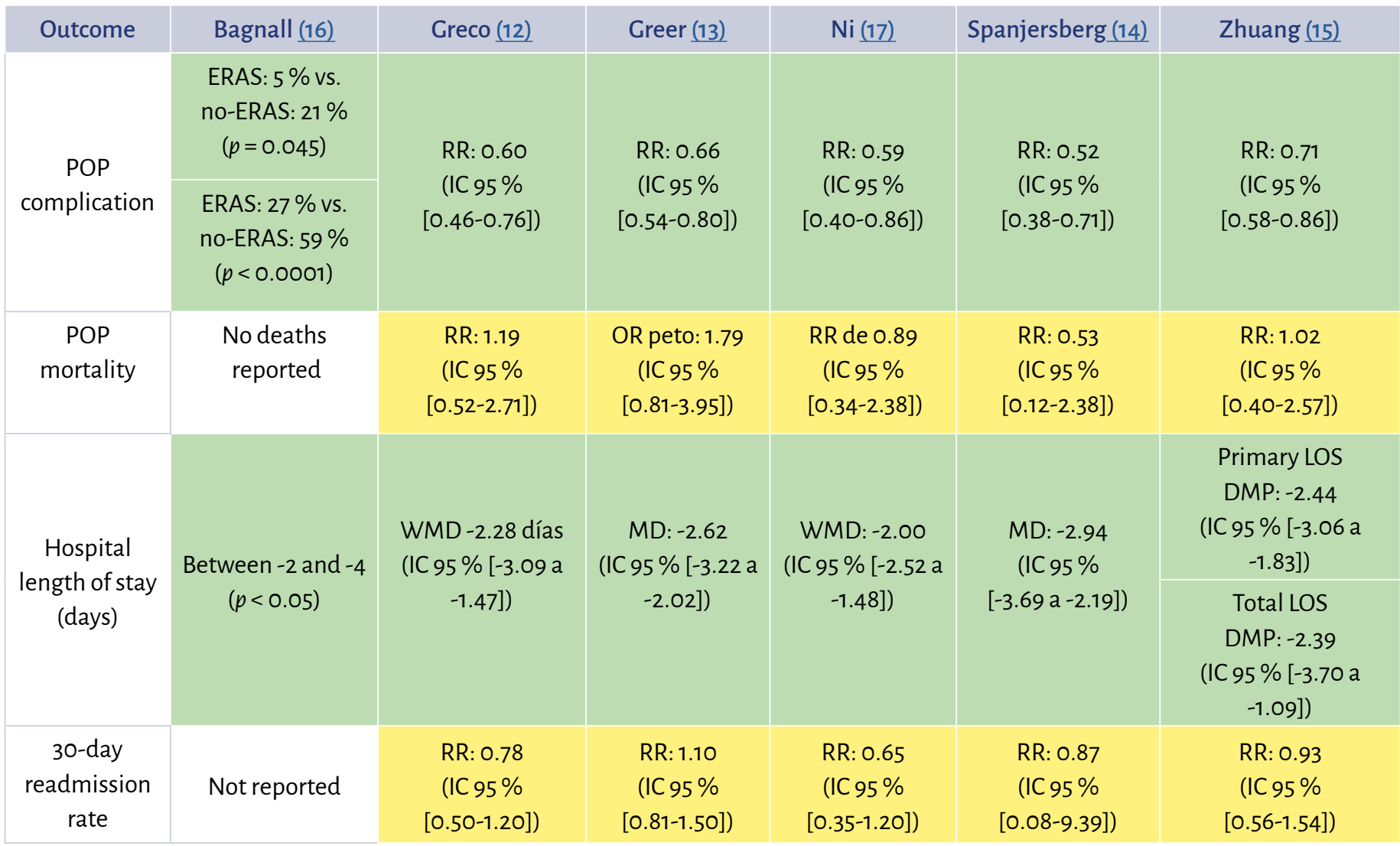

In favor of ERAS

No significant

differences

$\mathrm{Cl}$ : confidence interval, ERAS: enhanced recovery after surgery, MD: Mean difference, LOS: length of stay, OR: Odds Ratio, p: p value, POP: Postoperative, RR: Relative Risk, WMD: Weighted mean difference.

SOURCE: Authors.

between surgical complications (bleeding, need for reoperation and others) and nonsurgical complications (Foley catheter reinsertion or complication and aspiration/ infection pneumonia) as safety outcomes. There were no differences between the groups in terms of surgical complications, while the risk of non-surgical complications was lower with ERAS (RR: 0.40, 95\% Cl 95 [0.27-0.61]) (12); a similar finding was reported by Zhuang et al. for surgical complications (15).

According to Bagnall, respiratory complications were less frequent in the ERAS group, $5.1 \%$ vs. $16.4 \%$ ( $p<0.0001$ ) (16); like Greco, they found that ERAS was protective against these types of complications (RR: $0.41,95 \% \mathrm{Cl}$ [0.220.76]) and also against cardiovascular complications (RR: $0.51,95 \% \mathrm{Cl}$ [0.29$0.89]$ ); no differences were found in terms of urinary tract complications (RR: 0.39 , 95\% Cl [0.11-1.37]), although Bagnall et al. described higher urinary tract infection in elderly patients in the standard care group $4.3 \%$ vs. $11.2 \%$ ( $p=0.047$ ). There were no differences in anastomotic leak, surgical site infection or ileus $(p=0.86, p=0.14$ and $p=0.53$, respectively) (12).

$\mathrm{Ni}$ et al. found that ERAS reduced POP complications by $41 \%$ in patients undergoing laparoscopic colorectal surgery (RR: $0.59,95 \% \mathrm{Cl}$ [0.40 to 0.86$]$ ) (17), a finding that was also reported by Greer et al. in their subgroup analysis by surgical approach, with a $41 \%$ reduction in laparoscopic surgery (RR: $0.59,95 \% \mathrm{Cl}$ [0.39-0.90]), and risk reduction of $37 \%$ (RR: $0.63,95 \% \mathrm{Cl}$ [0.49-0.83]) in open surgery. In patients with colorectal cancer who received ERAS, the risk of postoperative morbidity dropped by $39 \%$ (RR: $0.61,95 \%$ $\mathrm{Cl}$ [0.46-0.80]), while this reduction was $52 \%$ in patients with rectal cancer (RR: 0.48 , 95\% Cl [0.27-0.88]) and 55\% in patients with benign conditions (RR: $0.45,95 \% \mathrm{Cl}$ [0.25-0.81]) (13).

Certainty in the findings for the postoperative complications outcome was 
very low and, consequently, it is subject to change in the light of new evidence, according to the GRADE methodology used to assess certainty of the body of evidencecorresponding to the SLR conducted by Greer et al.

\section{Readmission rate and mortality}

All the studies consistently reported absence of differences in these outcomes when the multimodal perioperative program was compared with traditional care $(13,15,17)$. Although, in their studies, Greco and Spanjersberg conducted sensitivity analyses using data from low/ moderate risk of bias studies, the results did not show any differences either (RR: 0.53, 95\% Cl [0.09-3.15]) (14). Certainty of the findings for postoperative mortality and readmission outcomes was very low and, therefore, subject to change in the light of new evidence.

\section{Length of hospital stay}

The six SLRs reported shorter LOS in favor of the multimodal care program. Bagnall found reductions ranging between 2.5 and 4 days (16). Zhuang made a distinction between primary and total LOS, the latter defined as primary plus LOS after readmission within the first 30 days of the surgery and, in both cases, described differences in favor of the program ( $p<$ 0.00001 ), with an average reduction of 2.44 days ( $95 \% \mathrm{Cl}$ [-3.06 to -1.83$])$ in primary LOS and 2.39 days $[-3,70$ to $-1,09]$ ) in total LOS (15). Greer, Greco and Spanjsberg reported similar findings (12-14).

In a meta-analysis of 24 studies, Greer et al. found a mean difference of 2.62 days in LOS reduction (MD: $-2.62,95 \% \mathrm{Cl}[-3.22$ to -2.02]) when ERAS was compared with traditional care. Depending on the surgical approach, they reported that in patients who underwent open surgery, the reduction was 2.55 days ( $95 \% \mathrm{Cl}[-3.43$ to -1.67$]$ ), while for laparoscopic surgery, the reduction was 2.76 days (95\% Cl [-3.58 to -1.93$]$ ).
Moreover, the reduction for patients with colorectal cancer was 2.88 days $(95 \% \mathrm{Cl}$ [-4.03 to -1.73$]$ ), 2.25 days ( $95 \% \mathrm{Cl}[-3.69$ to -0.81]) for patients with rectal cancer, and it was highest in benign conditions, at 3.16 days (95\% Cl [-3.97 to -2.34]) (13).

The certainty of the findings for the LOS outcome was very low and, therefore, subject to change in the light of new evidence.

\section{Other outcomes described}

Bagnall et al. reviewed time to ambulation and found it to be shorter in the ERAS group ( $p<0.001$ ) for patients $\geq 65$ years. Moreover, one of the included studies reported differences in favor of ERAS in terms of less cases of pulmonary and urinary tract infections, postoperative heart failure and delirium (16). Greer et al., on the other hand, found assessment of postoperative pain in only two studies and quality-oflife assessment in a single study, with no clinically significant changes (13).

Findings relating to gastrointestinal function showed differences in favor of the multimodal program. Greer et al. classified these outcomes as moderate, describing that, of the 22 studies in which return of intestinal function was assessed, 21 found differences, and of 14 which assessed time to resuming a solid diet, 13 found differences (13). Bagnall et al. and Zhuang et al. reported a shorter time interval to the first flatus (MD -1.02 days, $95 \% \mathrm{Cl}[-1.36$ to $-0.67])$ and to bowel movement (-1.12 days, $95 \% \mathrm{Cl}[-1.37$ to -0.87$])$; and also described positive results in the ERAS group for early fluid tolerance $(p<0.001)$ (15,16). Additionally, Spanjersberg et al. reported that patients receiving ERAS compared to standard care, tolerate initiation of oral intake 42 hours earlier $(p=0.042)$, solid diet three days earlier, with return of bowel activity two days earlier $(p<0.001)$ than patients receiving standard care (14).

In terms of adherence to the program, the study by Bagnall et al. was the only that looked specifically at the elderly. They observed that in patients over 64 there was less compliance with early initiation of fluids, solid diet and early catheter removal when compared to younger patients ( $p<$ 0.0001). In patients 75 and older, adherence to laparoscopic surgery was lower, while adherence to the use of abdominal drains was higher, when compared to patients between 64 and 74 years of age $(p<0.002)$. In patients over 79 years of age, adherence to bowel preparation, use of antiemetics and epidural analgesia was higher compared to the 70-79 age group, in which adherence to fluid restriction and early ambulation was higher (16).

Finally, the SLR conducted by Greer et al. was selected as the body of evidence because it was shown to be the most updated, it was given a moderate rating of confidence on the modified AMSTAR-2, and contained the primary studies which were included in the other SLRs reviewed (13). The results of the certainty evaluation using the GRADE methodology indicated that evidence certainty is very low, based on the fact that the primary studies included in the SLR showed a high or unclear risk of bias and high heterogeneity and nonevaluation of the publication risk by the authors of the SLR. The details of the results are shown in Table 4.

\section{DISCUSSION}

Surgical care is a critical component of medical care and contributes to social and economic development in general (4). Colorectal surgery is the treatment option that offers the highest probability of cure for colorectal disease, and perioperative care is an imperative challenge, given the increasing occurrence of this disease and the growing number of chronic diseases, such as cancer, in an aging population (1).

Postoperative complications are significantly frequent among patients undergoing colorectal surgery, affecting quality of life of both patients and families. Moreover, complications result in a substantial increase in healthcare-related costs due to longer hospital stay and the 
TABLE 4. Certainty of evidence.

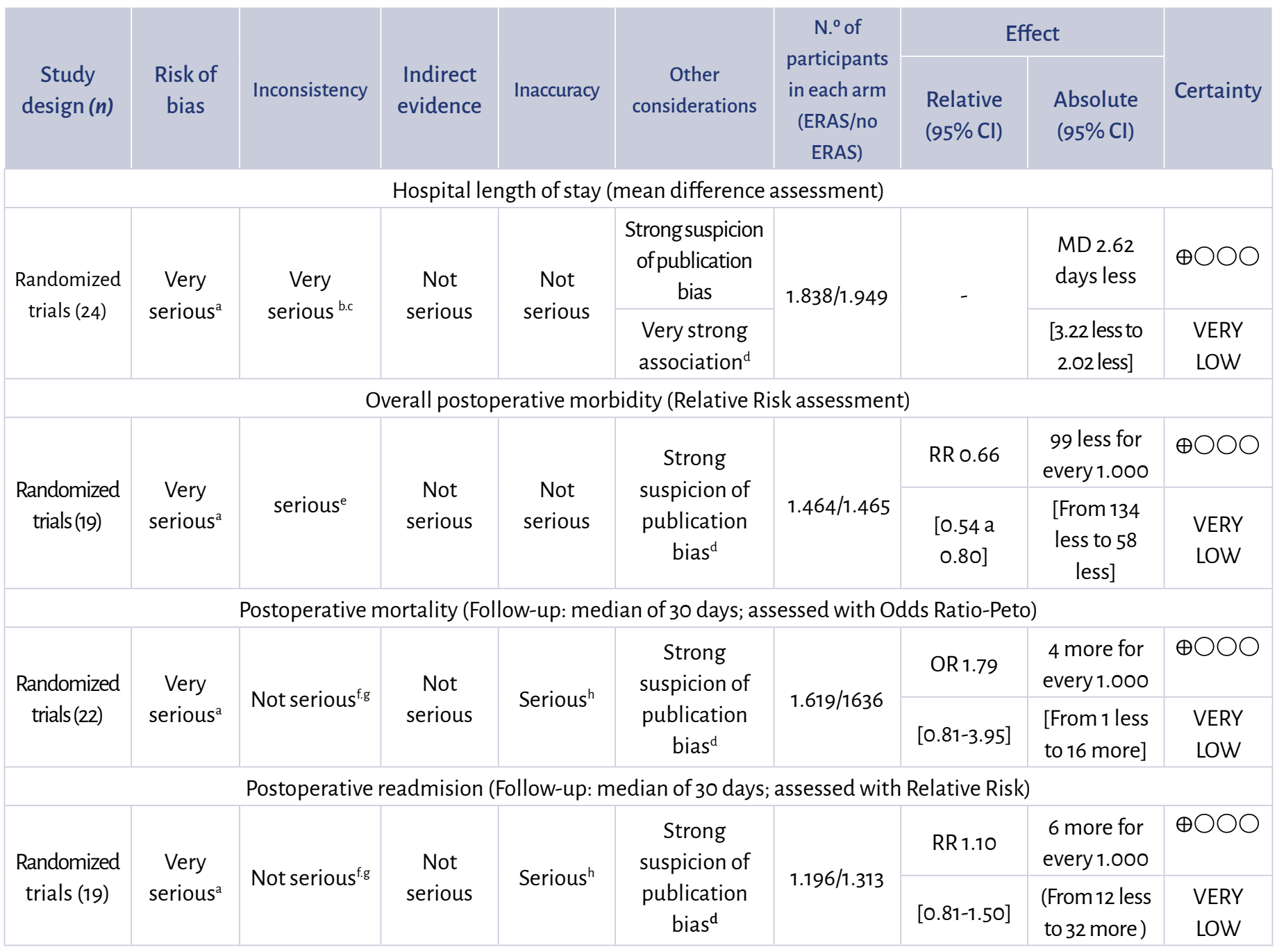

$\mathrm{Cl}$ : Confidence interval, ERAS: Enhanced recovery after surgery, MD: Mean difference, OR: Odds ratio, RR: Relative risk, SMD: Standardized mean difference.

a. Reports that the majority of the studies were shown to have a high and unclear risk of bias. b. Statistically substantial heterogeneity is reported ( $12>70 \%)$, unexplained in exploratory analyses on the basis of study design or length of stay in the control group. Despite high protocol variability between the two groups, the sensitivity analysis did not show changes in the combined effect. c. No Cl overlap. d. Dos not report publication bias assessment. e. HImportant heterogeneity: $12>40 \%<70 \%$. f. Cl overlap g. Low heterogeneity: I2 < 40. h. Narrow, non significant $\mathrm{Cl}$.

SOURCE: Authors.

need for additional procedures and care (3). This research was prompted by these issues and, having found a large number of secondary studies on the effectiveness and safety of the program of interest, it is considered to provide the most up-to-date evidence on the effectiveness and safety of multimodal perioperative care programs in colorectal surgery.
Although the amount of information retrieved reaffirms the concern regarding the course of the perioperative period, the evident methodological limitations of the studies may fuel the controversy or foster resistance to implementation. Moreover, it is important to underline the redundancy of SLRs that process information derived from the same primary studies, as had been reported in the review by Chambers et al. (18). The SLRs included in this review suggest that the implementation of the multimodal perioperative care program in colorectal surgery is effective at reducing overall postoperative mortality and hospital length of stay, but it does not offer conclusive results in terms of mortality and readmission rates. However, the certainty 
of the results is very low according to the CRADE methodology, which means that new research could result in changes in the estimated effect.

No significant results in favor of the program were reported for mortality or readmission rates, which might be explained by the low frequency of occurrence of these events and by the limited size of the primary studies included in the SLRs. It is also important to consider that short follow-up periods, restricted only to the period between hospital discharge and readmission, prevent any determination of strong long-term outcomes.

Because of the nature of the program, some of its components may have been implemented in control groups, defined as standard or traditional care in the primary studies. The components of the standard care were not spelled out clearly enough in the included reviews so as to allow the identification of differences between the intervention and the comparator. Although the bias that this could introduce against the program is recognized, results in terms of complications and LOS still favor the intervention.

Three limitations are recognized: first of all, the review protocol was not registered, considering that the review was conducted within the framework of a health technology assessment. However, it is worth explaining that the health technology assessment had a protocol which included the systematic review and was approved by the Ethics Committee of the Universidad Nacional of Colombia Medical School; second, no subgroup analyses were reported in accordance with a combination of program items and their relationship with outcomes so as to lead to program optimization and targeting towards specific outcomes associated with the particular needs of the institutions; third, issues associated with the most recent version of AMSTAR when applied to SLRs conducted before the update, as has been recognized by the developers of the tool (9). In this research, of the 33 SLRs found, 12 had to be excluded based on their quality assessment using AMSTAR-2, even though the research group introduced a modification in the rating, allowing the use of items categorized as partial which, in the tool, are considered as non-compliant; otherwise, only one SLR could have been considered. It is important to highlight that the modification to the rating tried to maintain high quality and was stringent in the assessment of the items related to risk of bias as well as search criteria.

An important consideration that calls researchers and clinicians to reflection is the relevance of patient-reported outcomes. Although our search focused on LOS, POP complications and mortality, none of the reviews included described qualityof-life or patient-reported outcomes, which are considered relevant for all decisions that involve them and their families, as reaffirmed by Street (19). It is expected that those outcomes will be considered in future research.

In conclusion, despite differential findings in favor of the multimodal perioperative program in colorectal surgery in terms of reduced POP complications and LOS reported in SLRs, the certainty of these findings is very low and, therefore, subject to change in the light of new evidence. Consequently, there is no certain evidence at the present time to recommend the implementation of this program in elective colorectal surgery. New research with good methodological quality and that includes patient-reported outcomes is required in order to provide a clear understanding of the benefits of the program.

\section{ETHICAL RESPONSIBILITIES}

\section{Ethics committee approval}

This research was approved on February 8, 2019, by the Ethics Committee of the Universidad Nacional of Colombia Medical School (Minutes No. No 002-014-19).

\section{Human and animal protection}

The authors declare that no human or animal experiments were carried out as part of this research.

\section{Data confidentiality}

The authors declare that the protocols of their institution pertaining to patient data disclosure were followed.

\section{Right to privacy and informed consent}

The authors declare that no patient information appears in this article.

\section{ACKNOWLEDGEMENTS}

\section{Authors' contributions}

All the authors participated in the design and conduction of the systematic review within the framework of a Master's thesis in Clinical Epidemiology. KC, EC, OC and JD worked on the idea and design of the study. KC and LR conducted the search and collected the data. $\mathbf{K C}, \mathbf{E C}, \mathbf{O C}, \mathbf{J D}, \mathbf{L R}$ interpreted the results and worked on the final drafting of the manuscript.

\section{Assistance for the study}

None declarated.

\section{Financial support and sponsorship}

None declarated.

\section{Conflict of interest}

None declarated.

\section{Presentations}

The preliminary results were presented during the public thesis defense at the Universidad Nacional of Colombia, in May 2019. 


\section{Appreciation}

The research team is grateful to the gastroenterology service specialists at the National Cancer Institute and to the chief of surgery at Clínica Reina Sofía for their contribution during the interviews on outcome prioritizations.

\section{REFERENCIAS}

1. Weiser TC, Haynes AB, Molina C, Lipsitz SR, Esquivel MM, Uribe-Leitz $T$, et al. Estimate of the global volume of surgery in 2012: an assessment supporting improved health outcomes. Lancet. 2015;385:S11. doi: http://doi. org/10.1016/S0140-6736(15)60806-6

2. van der Pas MHGM, Haglind E, Cuesta MA, Fürst A, Lacy AM, Hop WC], et al. Laparoscopic versus open surgery for rectal cancer (COLOR II): Short-term outcomes of a randomised, phase 3 trial. Lancet Oncol. 2013;14(3):210-8. doi: http://doi.org/10.1016/ S1470-2045(13)70016-0

3. Vonlanthen R, Slankamenac K, Breitenstein S, Puhan MA, Muller MK, Hahnloser D, et al. The impact of complications on costs of major surgical procedures: A cost analysis of 1200 patients. Ann Surg. 2011;254(6):907-13. doi: http://doi.org/10.1097/SLA.0b013e31821d4a43

4. Kehlet H, Wilmore DW. Multimodal strategies to improve surgical outcome. Am J Surg. 2002;183(6):630-41.

5. Miller TE, Thacker JK, White WD, Mantyh C, Migaly J, Jin J, et al. Reduced length of hospital stay in colorectal surgery after implementation of an enhanced recovery protocol. Anesth Analg. 2014;118(5):1052-61. doi: http:// doi.org/10.1213/ANE.0000000000000206

6. Pędziwiatr M, Wierdak M, Nowakowski M, Pisarska M, Stanek M, Kisielewski M, et al. Cost minimization analysis of laparoscopic surgery for colorectal cancer within the enhanced recovery after surgery (ERAS) protocol: a single-centre, case-matched study. Videosurgery Other Miniinvasive Tech. 2016;11(1):14. doi: http://doi.org/10.5114/wiitm.2016.58617

7. Jing $X$, Zhang $B$, Xing $S$, Tian L, Wang $X$, Zhou $M$, et al. Cost-benefit analysis of enhanced recovery after hepatectomy in Chinese Han population. Med (United States). 2018;97(34):e11957. doi: http://doi. org/10.1097/MD.0000000000011957

8. Portinari M, Ascanelli S, Targa S, Dos Santos Valgode EM, Bonvento $B$, Vagnoni $E$, et al. Impact of a colorectal enhanced recovery program implementation on clinical outcomes and institutional costs: A prospective cohort study with retrospective control. Int ] Surg. 2018;53:206-13. doi: http://doi.org/10.1016/j. ijsu.2018.03.005

9. Shea B], Reeves BC, Wells G, Thuku M, Hamel C, Moran ], et al. AMSTAR 2: A critical appraisal tool for systematic reviews that include randomised or non-randomised studies of healthcare interventions, or both. BM]. 2017;358:j4008. doi: http://doi.org/10.1136/bmj.j4008

10. Gaitán H, Rojas M, Alfonso ]. Búsqueda, evaluación y síntesis de la evidencia de efectividad y seguridad en evaluaciones de tecnología: Manual metodológico. BID; 2017. doi: http://dx.doi.org/10.18235/0000748

11. McMaster University. GRADEpro GDT: GRADEpro Guideline Development Tool [Software]. Evidence Prime, Inc. 2015.

12. Greco M, Capretti G, Beretta L, Cemma M, Pecorelli N, Braga M. Enhanced recovery program in colorectal surgery: A meta-analysis of randomized controlled trials. World ] Surg. 2014;38(6):1531-41. doi: http://doi.org/10.1007/ s00268-013-2416-8

13. Greer NL, Gunnar WP, Dahm P, Lee AE, MacDonald R, Shaukat A, et al. Enhanced recovery protocols for adults undergoing colorectal surgery: A Systematic review and meta-analysis. Dis Colon Rectum. 2018;61(9):1108-18. doi: http://doi.org/10.1097/ DCR.0000000000001160

14. Spanjersberg WR, Reurings ], Keus F, van Laarhoven C]. Fast track surgery versus conventional recovery strategies for colorectal surgery. Cochrane Database Syst Rev. 2011;(2):CDo07635. doi: http://doi. org/10.1002/14651858.cdoo7635.pub2

15. Zhuang C-L, Ye X-Z, Zhang X-D, Chen B-C, $Y u$ Z. Enhanced recovery after surgery programs versus traditional care for colorectal surgery: a meta-analysis of randomized controlled trials. Dis Colon Rectum. 2013;56(5):667-8. doi: http://doi.org/10.1097/ DCR.obo13e3182812842

16. Bagnall NM, Malietzis C, Kennedy RH, Athanasiou T, Faiz O, Darzi A. A systematic review of enhanced recovery care after colorectal surgery in elderly patients. Colorectal Disease. 2014. p. 947-56. doi: http://doi.org/10.1111/ codi. 12718

17. Ni X, Jia D, Chen $Y$, Wang L, Suo ]. Is the Enhanced Recovery After Surgery (ERAS) Program Effective and safe in laparoscopic colorectal cancer surgery? A Meta-analysis of randomized controlled trials. ] Gastrointest Surg Off ] Soc Surg Aliment Tract. 2019 Jul;23(7):1502-12. doi: http://doi.org/10.1007/s11605-019-04170-8

18. Chambers D, Paton F, Wilson P, Eastwood A, Craig D, Fox D, et al. An overview and methodological assessment of systematic reviews and meta-analyses of enhanced recovery programmes in colorectal surgery. BM] Open. 2014;4(5):e005014. doi: http://doi.org/10.1136/ bmjopen-2014-005014

19. Street AD. Dos estudios unicos en los que se destacan los efectos positivos _de los protocolos ERAS (Recuperación rápida después de cirugía) para la atención y la satisfacción de los pacientes. Colombian Journal of Anesthesiology. 2019;47(1):1-4. doi: http://doi. org/10.1097/cj9.0000000000000094 


\section{COMPLEMENTARY CONTENT}

COMPLEMENTARY CONTENT A. Search strategy.

\begin{tabular}{|c|c|c|c|}
\hline Database & Strategy (terms) & $\begin{array}{c}\text { Types of articles } \\
\text { and limits }\end{array}$ & $\begin{array}{l}\text { Search time } \\
\text { period }\end{array}$ \\
\hline Cochrane & $\begin{array}{l}\text { ((fast AND track) OR (ERAS) OR (Enhanced AND recovery AND Surgery)) } \\
\text { AND (colorectal OR colon OR Rectum OR Sigmoid) AND (surgery OR surgi- } \\
\text { cal OR procedure) in All Text - (Word variations have been searched) }\end{array}$ & Systematic reviews & $\begin{array}{l}\text { Up to February } \\
2020\end{array}$ \\
\hline Embase & $\begin{array}{l}\text { (('convalescence'/exp OR convalescen*:ab,ti OR (fast NEAR/5 trac- } \\
\text { k):ab,ti OR 'fast-track':ab,ti OR (recover* NEAR/5 surgery):ab,ti OR } \\
\text { eras:ab,ti OR (multimodal AND optimization:ab,ti) OR (enhanced } \\
\text { AND recovery:ab,ti)) AND (('colorectal surgery'/exp OR 'colon sur- } \\
\text { gery'/exp OR 'rectum surgery'/exp OR 'proctocolectomy'/exp OR (rec- } \\
\text { tum AND surgery) OR 'colon resection'/exp) OR (('surgery'/exp OR } \\
\text { resection:ab,ti OR surg*:ab,ti OR laparoscop*:ti,ab OR suturing:ab,ti) } \\
\text { AND ('colon'/exp OR 'rectum'/exp OR 'sigmoid'/exp OR colon*:ab,ti } \\
\text { OR colo*rectal:ti,ab OR rectum:ab,ti OR rectal:ab,ti OR sigmoid:ti,ab } \\
\text { OR proctocol*:ab,ti)))) AND ('meta analysis':kw OR 'meta analysis':it } \\
\text { OR 'review':it OR search) }\end{array}$ & Systematic reviews & $\begin{array}{l}\text { Up to February } \\
2020\end{array}$ \\
\hline Medline & $\begin{array}{l}\text { 1. exp Convalescence/ } \\
\text { 2. convalescen*.ab,ti. } \\
\text { 3. (fast adj5 track).ab,ti. } \\
\text { 4. fast-track.ab,ti. } \\
\text { 5. (recover* adj5 surgery).ab,ti. } \\
\text { 6. eras.ab,ti. } \\
\text { 7. } 1 \text { or } 2 \text { or } 3 \text { or } 4 \text { or } 5 \text { or } 6 \\
\text { 8. exp Colorectal Surgery/ } \\
\text { 9. exp Colectomy/ } \\
\text { 10. 'rectum surgery'.mp. } \\
\text { 11. exp Proctocolectomy, Restorative/ } \\
\text { 12. } 8 \text { or } 9 \text { or } 10 \text { or } 11 \\
\text { 13. surgery.mp. or exp General Surgery/ } \\
\text { 14. resection.ab,ti. } \\
\text { 15. surg*ab,ti. } \\
\text { 16. laparoscop*.ti,ab. } \\
\text { 17. suturing.ab,ti. } \\
\text { 18. } 13 \text { or } 14 \text { or } 15 \text { or } 16 \text { or } 17 \\
\text { 19. exp colon/ } \\
\text { 20. exp rectum/ } \\
\text { 21. exp Colon, Sigmoid/ } \\
\text { 22. colon*.ab,ti. } \\
\text { 23. colo*rectal.ti,ab. } \\
\text { 24. rect*.ab,ti. } \\
\text { 25. sigmoid.ab,ti. } \\
\text { 26. proctocol*.ab,ti. } \\
\text { 27. } 19 \text { or } 20 \text { or } 21 \text { or } 22 \text { or } 23 \text { or } 24 \text { or } 25 \text { or } 26 \\
\text { 28. } 18 \text { and } 27 \\
\text { 29. } 12 \text { or } 28 \\
\text { 30. multimodal optimization.mp. } \\
\text { 31. enhanced recovery.ab,ti. } \\
\text { 32. } 7 \text { or } 30 \text { or } 31 \\
\text { 33. } 29 \text { and } 32 \\
\text { 34. meta analysis.mp,pt. or review.pt. or search.tw. } \\
\text { 35. } 33 \text { and } 34 \\
\text { (a) }\end{array}$ & Systematic reviews & $\begin{array}{l}\text { Up to February } \\
2020\end{array}$ \\
\hline
\end{tabular}

SOURCE: Authors. 
Complementary CONTENT B. Excluded studies.

\begin{tabular}{|c|c|c|}
\hline Author, year & Title & Reason for exclusion \\
\hline Adamina, 2011 & $\begin{array}{l}\text { Enhanced recovery pathways optimize health outcomes and resource utilization: A meta- } \\
\text { analysis of randomized controlled trials in colorectal surgery }\end{array}$ & $\begin{array}{l}\text { AMSTAR-2: Critically low } \\
\text { confidence. }\end{array}$ \\
\hline Bolshinsky, 2018 & $\begin{array}{l}\text { Multimodal Prehabilitation Programs as a } \\
\text { Bundle of Care in Castrointestinal Cancer Surgery: A Systematic Review }\end{array}$ & $\begin{array}{l}\text { Does not correspond to the inter- } \\
\text { vention of interest. }\end{array}$ \\
\hline Chemali, 2016 & $\begin{array}{c}\text { Meta-Analysis: Postoperative Pain Management in Colorectal Surgical Patients and the } \\
\text { Effects on Length of Stay in an ERAS Setting. }\end{array}$ & $\begin{array}{l}\text { Does not correspond to the } \\
\text { intervention of interest. }\end{array}$ \\
\hline Eskicioglu, 2009 & $\begin{array}{l}\text { Enhanced Recovery after Surgery (ERAS) Programs } \\
\text { for Patients Having Colorectal Surgery: A Meta-analysis of Randomized Trials }\end{array}$ & $\begin{array}{l}\text { Primary studies included in another } \\
\text { report }\end{array}$ \\
\hline Gianotti, 2014 & $\begin{array}{l}\text { Enhanced recovery strategies in colorectal surgery: is the compliance with the whole pro- } \\
\text { gram required to achieve the target? }\end{array}$ & $\begin{array}{l}\text { AMSTAR-2: Critically low } \\
\text { confidence. }\end{array}$ \\
\hline Gillis, 2018 & $\begin{array}{c}\text { Effects of Nutritional Prehabilitation, With and Without Exercise, on Outcomes of Patients Who } \\
\text { Undergo Colorectal Surgery: A Systematic Review and Meta-analysis }\end{array}$ & $\begin{array}{l}\text { Does not correspond to the } \\
\text { intervention of interest. }\end{array}$ \\
\hline Gouvas, 2009 & Fast-track vs standard care in colorectal surgery: a meta-analysis update & AMSTAR-2: Low confidence. \\
\hline Grant, 2017 & $\begin{array}{l}\text { Impact of Enhanced Recovery After Surgery and Fast Track Surgery Pathways on Healthcare-as- } \\
\text { sociated Infections: Results From a Systematic Review and Meta-analysis }\end{array}$ & AMSTAR-2: Low confidence. \\
\hline Heiying, 2013 & A systematic review and meta-analysis of the safety pro le of fast-track surgery for colorectal surgery & AMSTAR-2: Critically low confidence. \\
\hline Lau, 2016 & Enhanced Recovery After Surgery Programs Improve Patient Outcomes and Recovery: A Meta-analysis & AMSTAR-2: Critically low confidence. \\
\hline $\begin{array}{l}\text { Launay-Savary, } \\
\qquad 2016\end{array}$ & $\begin{array}{l}\text { Are enhanced recovery programs in colorectal surgery feasible and useful in the elderly? A } \\
\text { systematic review of the literature }\end{array}$ & AMSTAR-2: Critically low confidence. \\
\hline Lemmens, 2009 & Clinical and Organizational Content of Clinical Pathways for Digestive Surgery: A Systematic Review & AMSTAR-2: Critically low confidence. \\
\hline Li, 2013 & $\begin{array}{l}\text { Fast-track rehabilitation vs conventional care in laparoscopic colorectal resection for colo- } \\
\text { rectal malignancy: A meta-analysis }\end{array}$ & AMSTAR-2: Critically low confidence. \\
\hline Lv, 2012 & $\begin{array}{l}\text { The enhanced recovery after surgery (ERAS) pathway for patients undergoing colorectal } \\
\text { surgery: an update of meta-analysis of randomized controlled trials }\end{array}$ & $\begin{array}{l}\text { Primary studies included in another } \\
\text { report }\end{array}$ \\
\hline Messenger, 2016 & $\begin{array}{l}\text { Factors predicting outcome from enhanced recovery programmes in laparoscopic colorec- } \\
\text { tal surgery: a systematic review }\end{array}$ & $\begin{array}{l}\text { Does not correspond to the } \\
\text { intervention of interest. }\end{array}$ \\
\hline Rawlinson, 2011 & A systematic review of enhanced recovery protocols in colorectal surgery & $\begin{array}{l}\text { Primary studies included in another } \\
\text { report }\end{array}$ \\
\hline Shao, 2014 & Fast-track surgery for gastroenteric neoplasms: a meta-analysis & AMSTAR-2: Low confidence. \\
\hline Spanjersberg, 2009 & Fast track surgery versus conventional recovery strategies for colorectal surgery (Protocol) & Protocol \\
\hline Spanjersberg, 2015 & $\begin{array}{l}\text { Systematic review and meta-analysis for laparoscopic versus open colon surgery with or } \\
\text { without an ERAS programme }\end{array}$ & AMSTAR-2: Low confidence. \\
\hline Varadhan, 2010 & $\begin{array}{c}\text { The enhanced recovery after surgery (ERAS) pathway for patients undergoing major electi- } \\
\text { ve open colorectal surgery: A meta-analysis of randomized controlled trials }\end{array}$ & AMSTAR-2: Low confidence. \\
\hline Walter, 2009 & Enhanced recovery in colorectal resections: a systematic review and meta-analysis & AMSTAR-2: Low confidence. \\
\hline Wang, 2017 & $\begin{array}{l}\text { A pooled analysis of fast track procedure vs. conventional care in laparoscopic colorectal } \\
\text { cancer surgery }\end{array}$ & $\begin{array}{l}\text { Primary studies included in another } \\
\text { report }\end{array}$ \\
\hline Wind, 2006 & Systematic review of enhanced recovery programmes in colonic surgery & AMSTAR-2: Low confidence. \\
\hline Yin, 2014 & $\begin{array}{l}\text { Comparison of fast track protocol and standard care in patients undergoing elective open } \\
\text { colorectal resection: a meta-analysis update }\end{array}$ & $\begin{array}{l}\text { Primary studies included in another } \\
\text { report. }\end{array}$ \\
\hline $\begin{array}{l}\text { Zargar-Shoshtari, } \\
\quad 2008\end{array}$ & Optimization of perioperative care for colonic surgery: a review of the evidence & $\begin{array}{l}\text { Does not correspond to the interven- } \\
\text { tion of interest. }\end{array}$ \\
\hline Zhao, 2014 & $\begin{array}{l}\text { Fast-track surgery versus traditional perioperative care in laparoscopic colorectal cancer } \\
\text { surgery: a meta-analysis }\end{array}$ & AMSTAR-2: Low confidence. \\
\hline FAGARD, 2019 & $\begin{array}{l}\text { A systematic review of the intervention components, adherence and outcomes of enhan- } \\
\text { ced recovery programmes in older patients undergoing elective colorectal surgery. }\end{array}$ & AMSTAR-2: Low confidence. \\
\hline
\end{tabular}

